\title{
¿Cómo habría sido la migración interna sin los altos niveles de violencia en México? Un análisis contrafactual municipal de las últimas dos décadas
}

\section{How would the internal migration have been without high levels of violence in Mexico? A municipal counterfactual analysis of the last two decades}

Oscar Rodríguez Chávez*

\section{Resumen}

Esta investigación analiza los efectos causales de la violencia sobre las tasas de emigración interna municipal en los municipios de mayor violencia en México durante las últimas dos décadas, a partir de escenarios contrafactuales de baja violencia. Los resultados muestran que, de haber tenido bajas tasas de homicidios, la emigración interna municipal desde los municipios más violentos del pais habría sido entre 10.4 y 21.8\% menor a lo observado, particularmente después del inicio de la denominada guerra contra el narcotráfico. Lo anterior evidencia el incremento de los desplazamientos internos forzados por la violencia en algunas regiones de México.

Palabras clave: violencia; desplazamiento interno forzado; análisis contrafactual; guerra contra el narcotráfico; homicidios; migración interna.

* El Colegio de la Frontera Norte, Departamento de Estudios de Población. Dirección: Insurgentes 3708, Fraccionamiento Los Nogales, Ciudad Juárez, Chihuahua, México. Correo: oscarrodriguez@colef.mx ORCID: https://orcid.org/00000002-7255-0605 


\begin{abstract}
Using counterfactual analysis, this paper analyzes the causal effects of violence on internal emigration rates in the municipalities with highest violence in Mexico during the last two decades. Results show that if municipalities with highest violence had low homicide rates, their internal emigration would have been between 10.4 and $21.8 \%$ lower than what was observed, particularly after the beginning of the so-called Mexican Drug War. Overall, findings shed light on the increase of violence-induced internal displacement in some regions of the nation.
\end{abstract}

Keywords: violence; forced internal displacement; counterfactual analysis; Mexican drug war; homicides; internal migration.

\title{
Introducción
}

El desplazamiento forzado en México se ha intensificado en las últimas dos décadas como resultado del incremento de la violencia e inseguridad en diversas regiones del país, dados los confrontamientos entre las fuerzas armadas con los grupos criminales, así como del enfrentamiento entre las organizaciones criminales por la producción, distribución y venta de diversos tipos de drogas en el interior y fuera de México. Pese a no contar con cifras oficiales acerca de la magnitud del problema, organizaciones como el Internal Displacement Monitoring Centre (IDMC, 2018) han estimado que entre 2009 y 2017 se han desplazado de forma directa por cuestiones de inseguridad y/o violencia cerca de 345 mil personas, particularmente de municipios del norte, occidente y sureste de la nación.

No obstante, estas estimaciones dejan fuera las causas indirectas de la violencia que pueden propiciar la migración interna e internacional de miles de personas, particularmente en regiones del país en donde la violencia tuvo crecimientos exponenciales en las últimas dos décadas, lo que repercutió en el bienestar social y económico de las familias, que a largo plazo incentivó la migración de personas sin que éstas fueran directamente violentadas.

Para estimar los efectos de la violencia en la emigración interna de los municipios más violentos de México, así como su evolución, 
este análisis parte de la caracterización y localización de los municipios de mayor violencia en las últimas dos décadas, para posteriormente analizar los efectos causales que ha tenido ésta sobre el incremento de las tasas de emigración interna en dichos municipios, mediante la construcción de escenarios hipotéticos de baja violencia que son contrastados con lo observado, lo que permite conocer los efectos reales que ha tenido la violencia sobre los movimientos poblacionales en el interior del país. Esto constituye un primer paso en cuantificar el problema, que podría permitir el diseño de políticas públicas que prevengan, protejan y atiendan a las víctimas del desplazamiento forzado en México.

\section{Violencia y migración forzada a nivel global}

Existen diversas causas por las que las personas migran dentro o fuera de sus países: desde causas sociales, económicas, laborales y familiares que incentivan a las personas a moverse (Acosta y Cruz, 2016; Massey et al., 1993), hasta conflictos, guerras, violencia generalizada, desarrollo de megaproyectos como presas, aeropuertos y minas, así como desastres por inundaciones, terremotos y sequías, entre otros fenómenos que pueden poner en peligro la vida de las personas, obligándolas a desplazarse de manera forzada (ONU, 1998).

Los desplazamientos forzados, a diferencia de la migración que comúnmente se debe a determinantes laborales o familiares, responden a cambios de residencia obligada como resultado de uno o más factores estresantes. Según estimaciones de la ACNUR (2018), entre 1996 y 2017 la población desplazada en el mundo pasó de 37.3 millones a 68.5 millones, es decir 83.6\% más, mientras que, en el mismo periodo, según datos del Banco Mundial (2018) la población tuvo un crecimiento de $29.9 \%$, al pasar de 5.8 mil millones a $7.5 \mathrm{mil}$ millones de personas. Este incremento de los desplazamientos forzados se explica en su mayoría por las situaciones de violencia generalizada en diversos países y regiones de Asia, África y América Latina.

Del total de desplazados forzados hasta 2017 , cerca de $40 \mathrm{mi}$ llones no habían cruzado una frontera internacional, por lo que se 
les considera personas internamente desplazadas (PID); mientras que 28.5 millones sí cruzaron una frontera internacional, considerándoseles refugiados o solicitantes de asilo en los países de destino. Dentro de los países expulsores con más personas refugiadas se encuentran: Siria, Afganistán, Sudán del Sur, Myanmar y Somalia, cuyos conflictos, crisis y guerras han provocado la salida de más de 13 millones de personas. En tanto que los países con mayor número de desplazamientos internos fueron: Colombia, Siria, República del Congo, Irak, Somalia, Yemen, Sudán, Sudán del Sur, Afganistán y Ucrania, con más de 35 millones de personas que se desplazaron en gran parte por los mismos motivos que los refugiados (ACNUR, 2018).

\section{Incremento de la violencia y de los desplazamientos forzados en México}

Pese a que los niveles de desplazamiento interno forzado en México no se comparan con los de países como Colombia o Siria, este fenómeno se ha dado en el país desde las décadas de los setenta y ochenta, resultado de conflictos comunales, territoriales y religiosos que provocaron el desplazamiento de cientos y miles de personas en entidades como Guerrero, Oaxaca, Chiapas y Nayarit (CNDH, 2016). Sin embargo, su principal crecimiento se dio a partir de la década de los noventa en el estado de Chiapas, a consecuencia de los enfrentamientos entre grupos militares e integrantes del Ejercito Zapatista de Liberación Nacional (EZLN), que provocaron la migración interna municipal de hasta 30 mil personas entre 1994 y 2011 (CMDPDH, 2014).

A inicios del siglo XXI las condiciones de seguridad y de violencia en México cambiaron particularmente en algunas regiones del norte y occidente como resultado de la estrategia de seguridad implementada por el presidente Felipe Calderón en diciembre de 2006, la cual consistió a grandes rasgos en el confrontamiento directo de las fuerzas armadas -el Ejército, la Marina y la Policía Federal- contra los grupos del crimen organizado, en especial contra algunos de los principales carteles de drogas en México al declararles la guerra y establecer como prioridad el abatimiento de sus líderes (CMDPDH, 2014; Martínez, 2016). 
Esto trajo como resultado el aumento de la violencia en diversas regiones del país, ante la captura o muerte de algunos de los principales líderes del narcotráfico y la posterior división y enfrentamiento entre las organizaciones criminales por la producción, distribución y venta de drogas en México y en Estados Unidos (IDMC, 2018). Además, algunos de estos grupos diversificaron sus fuentes de ingresos al cometer otros delitos como secuestros, extorsiones, trata de personas y robos, lo que provocó el aumento de la violencia y de su percepción en diversas regiones del país, en especial en la región norte y en Guerrero, Michoacán y Jalisco (CNDH, 2016; Vélez et al., 2015).

El aumento y concentración de la violencia e inseguridad en algunas zonas del país provocaron varios problemas: el incremento de los costos directos e indirectos de la delincuencia (Vélez et al., 2015), la disminución de la esperanza de vida (Aburto et al., 2016) y el desplazamiento forzado de personas dentro y fuera de México (Gutiérrez y Rivero, 2012; Ramírez y Meza, 2012). En este sentido, trabajos como el de Acosta y Cruz (2015) han encontrado que las condiciones actuales de la calidad de vida de las personas han tenido un impacto significativo sobre los movimientos poblacionales recientes en el interior de algunas entidades mexicanas: la violencia y la marginación para el periodo 2005-2010 tuvieron efectos significativos en estados como Chihuahua y Durango, que sufrieron graves problemas de seguridad.

\section{Persecuciones directas versus desplazamientos indirectos o de contexto}

La violencia puede tener tanto efectos directos como indirectos en el bienestar social y económico de las personas. Por un lado, los actores que generan violencia pueden ejercerla directamente sobre las personas a través de amenazas, extorsiones, secuestros, robos, lesiones e inclusive llegar al homicidio de algún conocido o miembro del hogar, lo que los obliga a salir de forma forzada y reactiva de sus comunidades de origen como estrategia para salvaguardar sus vidas (Ibáñez y Vélez, 2008; CMDPH, 2019). 
Sin embargo, los mismos actores generadores de violencia pueden llegar a repercutir en el contexto social y económico de terceros, al representar un factor estresante para el desarrollo social y económico de las personas que viven con el temor de ser víctimas de estos actores, particularmente en contextos prolongados de violencia generalizada y de diversos tipos de conflictos y guerras. A la larga esto puede motivar a las personas a abandonar sus lugares de origen, pese a no haber sido víctimas directas de la violencia (Bariagaber, 1997; Morrison, 1993).

Lo anterior se complementa con investigaciones como la de Morrison (1993) en Guatemala, Alvarado y Massey (2010) en Norte y Centroamérica, y Ramírez y Meza (2012) en México, que concuerdan en que los desplazamientos forzados no se dan hasta que el nivel de violencia en una región es tal, que impide el pleno desarrollo económico y social de las personas, forzándolas a migrar a otros lugares dentro y fuera de sus países. Antes de este nivel, los altos costos sociales y económicos del desplazamiento superan a los costos de permanecer en los lugares de origen.

No obstante, la mayor parte de las investigaciones y encuestas tratan de medir los efectos directos de la violencia sobre la migración interna e internacional, sin tomar en cuenta que la violencia puede provocar cambios económicos y sociales que motivan a las personas a moverse de sus lugares de origen. Al respecto, Bariagaber (1997), en una investigación sobre migración y violencia en Etiopía, menciona que la violencia puede provocar tanto desplazamientos directos como indirectos, resultado de la reducción o pérdida económica de las fuentes de ingresos de las personas o de sus medios de producción, lo que a largo plazo puede llevarlas a migrar sin que éstas fueran necesariamente amenazadas o violentadas.

En este sentido, Gutiérrez y Rivero (2012) buscan estimar los efectos tanto directos como indirectos de la violencia en México sobre la migración interna de los municipios más violentos de doce entidades del país para el periodo 2005-2010, en donde una vez controlando diversos factores asociados con la violencia, y mediante la creación de escenarios contrafactuales, estiman la emigración interna que estos municipios hubieran tenido de no haber experimentado altos niveles de violencia, llegando a la conclusión que en promedio 
su emigración, de haber tenido bajas tasas de violencia, hubiera sido 4.5 veces menor a lo observado.

Sin embargo, las autoras dejan fuera del análisis a otros municipios con altos niveles de violencia en México, además de sólo limitarse a 2005-2010, dejando fuera los periodos previo y posterior a la puesta en marcha de la estrategia de seguridad de 2007, que pudieron haber incrementado los efectos como resultado del aumento de los homicidios y de otros delitos relacionados con el crimen organizado.

\section{Migración a Estados Unidos}

Los incrementos de la violencia en algunas regiones de México, particularmente en la frontera norte del país, han provocado desplazamientos a Estados Unidos, cuya política migratoria en años recientes ha dificultado el acceso al estatus de refugiado, por lo que algunos mexicanos han buscado otras formas de poder ingresar, ya sea de manera documentada (visas de turista, negocios e inversiones) o indocumentada, dependiendo de sus recursos económicos y de las redes migratorias con las que cuentan, como lo han estudiado Durin (2012) y Morales et al. (2013).

Ramírez y Meza (2012) miden el efecto de la violencia sobre la migración mexicana hacia Estados Unidos para el periodo 20052010; encuentran que el aumento de la violencia en algunos municipios mexicanos ha provocado el incremento de la migración internacional hacia ese país. No obstante, observan que esta relación no es lineal sino en forma de $U$ invertida, pues no es hasta que se supera un determinado umbral de violencia cuando ésta muestra un efecto significativo sobre el incremento de la migración internacional en los municipios de México.

Para el caso particular de las ciudades en la frontera norte de México, Ríos (2014) encuentra que sus patrones de migración internacional a Estados Unidos responden principalmente a problemas de seguridad, violencia y temor a los grupos criminales, particularmente después de 2008, estimando que alrededor de 265 mil mexicanos en estas ciudades habían migrado por temor a las organizaciones criminales durante el periodo 2006 a 2010. 


\section{El presente estudio: un análisis contrafactual}

Para abonar a esta literatura y contribuir al conocimiento de los efectos de la violencia sobre la emigración interna municipal en las regiones más violentas de México en años recientes, este trabajo tiene como objetivos determinar, en principio, cómo se ha distribuido geográficamente la violencia y la emigración interna municipal en el país en las últimas dos décadas; para posteriormente, a partir del reconocimiento y localización de los municipios con mayores problemas de violencia, medir los efectos que han tenido sus altos niveles de violencia sobre sus tasas de emigración interna, mediante la creación de escenarios contrafactuales de bajos niveles de violencia.

Esta estrategia metodológica de escenarios contrafactuales ha sido utilizada frecuentemente para medir los efectos de un tratamiento o de una política pública sobre el bienestar de las personas o municipios que fueron beneficiados. Por ejemplo, para medir los efectos de programas de salud (Arenas et al, 2015) y programas de desarro1lo (Cerón y Hernández, 2017), o para medir otro tipo de fenómenos como los efectos de las remesas sobre los niveles de pobreza de los hogares (Esquivel y Huerta-Pineda, 2007) y los efectos de la violencia sobre la migración (Gutiérrez y Rivero, 2012).

Primero se estiman las tasas esperadas de emigración interna de no haber experimentado altas tasas de violencia municipal, y posteriormente se comparan con las tasas reales observadas con el fin de determinar los efectos totales de la violencia en los municipios con mayores niveles de violencia en México para los periodos 1995$2000,2005-2010$ y 2010-2015. Se espera que la violencia en estos municipios haya provocado el desplazamiento forzado interno de miles de personas, particularmente en regiones del norte y en algunos municipios del occidente del país, ya sea como resultado directo de la violencia o como consecuencia de la disminución de su bienestar social y económico provocado por efectos indirectos de la violencia.

Por lo tanto, los efectos totales de la violencia pueden llegar a ser mayores a los de las estimaciones de encuestas e investigaciones que únicamente han abordado los desplazamientos forzados directos de las personas. Por otro lado, se espera que los efectos de la violencia 
sobre las tasas de emigración interna municipal sean mayores en el periodo 2010-2015, posterior a la puesta en marcha de la estrategia de seguridad implementada en 2007, lo que ocasionó el aumento de la violencia, en especial en algunas regiones del norte y occidente del país, y por ende el incremento de los desplazamientos directos e indirectos en estas regiones.

\section{Datos}

Esta investigación usa los microdatos de los Censos de Población y Vivienda (CPV) de 2000 y 2010 y de la Encuesta Intercensal (EI) 2015 del Instituto Nacional de Estadística y Geografía (INEGI), dado que cuentan con un nivel de desagregación a nivel municipal de las características socioeconómicas, demográficas y migratorias del total de municipios en México. ${ }^{1}$ Para poder llevar a cabo el análisis, se usan los datos ponderados a nivel municipal durante los tres periodos obtenidos: 1995-2000, 2005-2010 y 2010-2015. Además, estos datos se complementan con otras características socioeconómicas y demográficas de los municipios relacionados con los determinantes de la migración interna y de la violencia en México propuestos por Acosta y Cruz (2015), Gutiérrez y Rivero (2012) y Enamorado, López-Calva y Rodríguez Castelán (2014), que fueron obtenidos a partir de bases de datos del Consejo Nacional de Población (Conapo), del Consejo Nacional de Evaluación de la Política de Desarrollo Social (Coneval), de los registros administrativos del INEGI, y del Centro de Investigación y Docencia Económicas (CIDE) (véase el resumen de variables en el Cuadro 1).

\section{Variables $e$ indicadores}

Esta investigación se centra en conocer los cambios en los niveles de emigración interna de los municipios de México, para lo cual se hace

${ }^{1}$ No se utiliza el Conteo de Población y Vivienda 2005 pues no permite desagregar los flujos de migración interna municipal. 
uso de las tasas de emigración interna municipal por años-persona construidas a partir de la pregunta de lugar de residencia (municipio) cinco años atrás, y de la población municipal contenida en los CPV 2000 y 2010, el conteo de población 2005 y de la EI 2015, en donde los años-persona de cada municipio se calculan a partir de:

$$
A P_{(t 1, t 2)}=\frac{N_{(t 2)}-N_{(t 1)} *[T]}{\ln \left[\frac{N_{(t 2)}}{N_{(t 1)}}\right]}
$$

donde:

$A P_{(t 1, t 2)}$ son los años-persona del municipio $i$ entre $t 1$ y $t 2$ $N_{(t 2)}$ es la población total del municipio $i$ en el tiempo $t 2$ $\mathrm{N}_{(t 1)}$ es la población total del municipio $i$ en el tiempo $t 1$ $T$ es el periodo de cinco años.

Y la tasa de emigración interna municipal en años-persona se calcula como:

$$
\operatorname{TEIm}_{i}=\frac{\operatorname{EMI}_{(t 1, t 2) i j}}{A P_{(t 1, t 2)}} * 1000
$$

donde:

$T_{E I m_{i}}$ es la tasa de emigración interna del municipio $i$ en años persona

$E M I_{i}$ es el total de emigrantes internos del municipio $i$ en el periodo $t 1$ a $t 2$

$A P_{(t 1, t 2)}$ son los años-persona del municipio $i$ entre $t 1$ y $t 2$.

Respecto a la variable causal o de tratamiento de los municipios, ésta se construye a partir de la selección del 20\% de los municipios con mayores niveles de violencia en México, ${ }^{2}$ la cual se calcula a

${ }^{2}$ Esto como resultado de trabajos previos, en donde se encontró que particularmente los municipios de los deciles XI y X de violencia (los de mayor violencia) 
partir de las tasas de homicidios municipales por cada mil habitantes en periodos de cinco años a partir de los registros administrativos del INEGI (2019). Esta variable ha sido utilizada en otros estudios que relacionan a la migración con la violencia e inseguridad (Alvarado y Massey, 2010; Ramírez y Meza, 2012; Gutiérrez y Rivero, 2012; CMDPDH, 2019), dado el menor subregistro en comparación con otros delitos y por el impacto que tiene sobre la percepción de seguridad de las personas que habitan una comunidad o región. ${ }^{3}$

El resto de las características o variables de control que pueden llegar a estar asociadas con la violencia y la emigración interna en los municipios de México durante los tres periodos de análisis se dividen en tres dimensiones: social, demográfica y económica. Se sigue lo utilizado en las investigaciones de Acosta y Cruz (2015), Gutiérrez y Rivero (2012) y Enamorado, López-Calva y Rodríguez-Castelán (2014), las cuales hacen uso de los CPV 2000 y 2010, de la EI 2015 y de otras bases de datos de Conapo, Coneval e INEGI. En el Cuadro 1 se muestra cada una de éstas, su definición, operacionalización, fuente de datos y disponibilidad en el tiempo.

Además de estas variables, dado el interés de este trabajo por analizar la violencia ejercida por los grupos criminales y en particular de los grupos del narcotráfico en México, se hace uso de la base de datos del Programa de Política de Drogas (PPD) del CIDE, particularmente del registro de ejecuciones durante la denominada "guerra contra las drogas" para el periodo diciembre de 2006 a noviembre de $2011 \mathrm{y}$ del registro de narcomensajes dejados en las ejecuciones durante este periodo. ${ }^{4}$

mostraban altas tasas de emigración y bajas tasas de inmigración, dando como resultado un mayor número de saldos netos negativos en estos deciles.

${ }^{3}$ La Oficina de las Naciones Unidas contra la Droga y el Delito (UNODC, 2013) ha establecido como indicador general de la violencia a los homicidios puesto que este delito no sólo tiene un fuerte impacto en la percepción de las personas sobre inseguridad y violencia, sino también presenta un menor subregistro en comparación con otro tipo de delitos.

${ }^{4}$ Pese a que esta base de datos únicamente permite obtener información para el periodo de análisis 2006-2010, la información permite determinar el efecto y sentido de la presencia de grupos criminales en los municipios (variable omitida en el resto 


\section{Cuadro 1}

Indicadores municipales asociados a la violencia y la migración interna en México, 1995-2015

\begin{tabular}{|c|c|c|c|c|}
\hline & Indicador & Definición (tipo) & $\begin{array}{c}\text { Fuente de } \\
\text { información }\end{array}$ & Años disponibles \\
\hline & $\begin{array}{l}\text { Emigración } \\
\text { interna } \\
\text { (v. dependiente) }\end{array}$ & $\begin{array}{l}\text { Tasa emigración } \\
\text { interna municipal } \\
\text { en años-persona } \\
\text { (continua) }\end{array}$ & $\begin{array}{l}\text { CPV y EI } \\
\text { (INEGI) }\end{array}$ & $2000,2010,2015$ \\
\hline \multirow{6}{*}{$\begin{array}{l}0 \\
\frac{0}{\pi} \\
0 \\
0 \\
0\end{array}$} & $\begin{array}{l}\text { Municipios con } \\
\text { alta violencia } \\
\text { (v. tratamiento) }\end{array}$ & $\begin{array}{l}20 \% \text { de los mu- } \\
\text { nicipios con } \\
\text { mayores tasas de } \\
\text { homicidios por } \\
\text { cada mil habs. } \\
\text { (dummy) }\end{array}$ & $\begin{array}{l}\text { Registros ad- } \\
\text { ministrativos } \\
\text { (INEGI) }\end{array}$ & $1990-2016$ \\
\hline & $\begin{array}{l}\text { Enfrentamientos } \\
\text { entre grupos } \\
\text { criminales }\end{array}$ & $\begin{array}{l}\text { Presencia narco- } \\
\text { mensajes en ase- } \\
\text { sinatos (dummy) }\end{array}$ & CIDE (PPD) & 2006-2011 \\
\hline & Marginación & $\begin{array}{l}\text { Grado margina- } \\
\text { ción municipal } \\
\text { (categórica): muy } \\
\text { bajo, bajo, medio, } \\
\text { alto y muy alto }\end{array}$ & Conapo & $\begin{array}{l}1990,2000,2005, \\
2010,2015\end{array}$ \\
\hline & $\begin{array}{l}\text { Redes migratorias } \\
\text { internas }\end{array}$ & $\begin{array}{l}\text { Porcentaje pob. } \\
\text { nacida en otro } \\
\text { municipio de Mé- } \\
\text { xico (continua) }\end{array}$ & $\begin{array}{l}\text { CPV y EI } \\
\text { (INEGI) }\end{array}$ & $2000,2010,2015$ \\
\hline & $\begin{array}{l}\text { Redes migratorias } \\
\text { internacionales }\end{array}$ & $\begin{array}{l}\text { Índice absoluto } \\
\text { de intensidad } \\
\text { migratoria } \\
\text { municipal } \\
\text { (continua) }\end{array}$ & Conapo & 2000,2010 \\
\hline & Desigualdad & $\begin{array}{l}\text { Gini municipal } \\
\text { (continua) }\end{array}$ & Coneval & $\begin{array}{l}1990,2000,2005, \\
2010\end{array}$ \\
\hline
\end{tabular}

de los periodos) y su impacto sobre el aumento o reducción de la violencia medida a partir de las tasas de homicidios municipales quinquenales. 


\begin{tabular}{|c|c|c|c|c|}
\hline & Indicador & Definición (tipo) & $\begin{array}{c}\text { Fuente de } \\
\text { información }\end{array}$ & Años disponibles \\
\hline \multirow{2}{*}{ 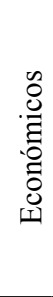 } & Salario & $\begin{array}{l}\text { Mediana del } \\
\text { ingreso por tra- } \\
\text { bajo/1000 por } \\
\text { municipio (con- } \\
\text { tinua) }\end{array}$ & $\begin{array}{l}\text { CPV y EI15 } \\
\text { (INEGI) }\end{array}$ & $2000,2010,2015$ \\
\hline & Empleo & $\begin{array}{l}\text { Porcentaje pob. } \\
\text { desocupada muni- } \\
\text { cipal (continua) }\end{array}$ & $\begin{array}{l}\text { CPV y EI15 } \\
\text { (INEGI) }\end{array}$ & $2000,2010,2015$ \\
\hline \multirow{2}{*}{ 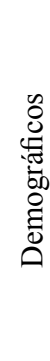 } & $\begin{array}{l}\text { Presión } \\
\text { demográfica }\end{array}$ & $\begin{array}{l}\text { Relación pob. de } \\
14 \text { a } 25 \text { años entre } \\
\text { la de } 45 \text { a } 64 \text { años } \\
\text { x } 100 \text { (continua) }\end{array}$ & $\begin{array}{l}\text { CPV y EI15 } \\
\text { (INEGI) }\end{array}$ & $2000,2010,2015$ \\
\hline & Urbanización & $\begin{array}{l}\text { Pob. municipal } \\
\text { (dicotómica). Ru- } \\
\text { ral: menos de } 15 \\
\text { mil habs. Urba- } \\
\text { no: } 15 \text { mil o más } \\
\text { habs. }\end{array}$ & $\begin{array}{l}\text { CPV y EI15 } \\
\text { (INEGI) }\end{array}$ & $2000,2010,2015$ \\
\hline
\end{tabular}

Fuente: Elaboración propia.

\section{Método}

Después de un análisis descriptivo de la evolución geográfica de la violencia y la emigración interna municipal en el periodo de estudio, y de las características sociodemográficas de los municipios con altos niveles de violencia, esta investigación procede a crear un escenario contrafactual para los municipios más violentos de México, lo cual ayuda a cuantificar los efectos de la violencia sobre las tasas de emigración interna municipal a través de la técnica de Propensity Score Matching y de distintos métodos de emparejamiento de los municipios.

Este tipo de técnicas cuasi experimentales surge del problema de los trabajos observacionales para poder tener dos grupos seleccionados de manera aleatoria, en donde a uno se le da un tratamiento y al otro no, por lo que pueden llegarse a generar resultados sesgados 
acerca de los efectos del tratamiento dada la existencia de factores de confusión que estén ligados a que un individuo reciba o no el tratamiento (Esquivel y Huerta-Pineda, 2007).

Esencialmente, esta metodología parte de suponer a los municipios del país con los mayores niveles de violencia como municipios con "tratamiento", para posteriormente compararlos con otros municipios de iguales características, pero con niveles menores de violencia o "sin tratamiento". No obstante, dada la dificultad de poder hallar a municipios tratados y no tratados con iguales características socioeconómicas y demográficas observadas, es que se hace uso de la técnica de Propensity Score Matching para generar un índice de propensión que permita emparejar a municipios tratados y no tratados con características similares, en donde sólo varíe su nivel de violencia observado.

La técnica de Propensity Score Matching resume las características socioeconómicas y demográficas de los municipios en un índice que permite comparar a municipios tratados y no tratados con similares características para así obtener el efecto promedio del tratamiento; en donde el Propensity Score se define como la probabilidad condicional de que un municipio pertenezca al grupo de tratamiento (Esquivel y Huerta, 2007; Rosenbaum y Rubin, 1983), en este caso al $20 \%$ de los municipios más violentos del país, dado un conjunto de variables observadas $X$ :

$$
p(X)=\operatorname{Pr}[T=1 \mid X]=E[T \mid X]
$$

donde:

$p(X)=F\left(h\left(X_{i}\right)\right)$

$F($.) es la distribución logística acumulada

$T=1$ si el municipio recibió tratamiento y 0 si no lo recibió

$X$ es el vector de características socioeconómicas y demográficas antes del tratamiento.

Posteriormente, una vez computada la puntuación de la propensión, el efecto promedio de los municipios tratados (ATE) puede ser estimado según Baum (2013) como: 


$$
\mathrm{ATE}=E[Y(1)-Y(0)]=E[Y(1)]-E[Y(0)]
$$

donde:

$Y(1)$ es el resultado posible si el municipio recibió tratamiento $Y(0)$ es el resultado posible si el municipio no recibió tratamiento.

Mientras que el efecto promedio del tratamiento entre los tratados se calcula como:

$$
\mathrm{ATT}=E[Y(1)-Y(0) / T=1]=E[Y(1) / T=1]-E[Y(0) / T=1]
$$

Una vez que se tienen los índices de propensión, el emparejamiento de municipios tratados (violentos) con municipios no tratados (no violentos), pero con similares características observables, se puede realizar mediante diversos métodos de coincidencia, entre los que se encuentran el de vecino más cercano, radio y Kernel.

El método del vecino más cercano consiste esencialmente en evaluar las diferencias absolutas entre los puntajes de propensión y emparejar a los municipios con puntuaciones de propensión lo más cercanas posibles, para lo cual se toman $k$ vecinos para cada uno de los municipios tratados, en este caso dos vecinos, y se excluye al resto de los municipios no tratados y no emparejados (Baum, 2013). Por tanto, en este método cada municipio tratado tiene a dos municipios no tratados lo más cercano posible a su índice de propensión.

Una variante a este método es el método del radio, que consiste en definir un vecindario dentro del cual los municipios de control puedan considerarse como vecinos para el emparejamiento con los municipios tratados, en donde es necesario considerar el tamaño del radio ( 0.01 en este caso) ya que si éste es muy pequeño, pueden quedar fuera municipios con tratamiento; mientras que si es muy grande, se incluye a todos los municipios tratados, pero pueden ser mayores los rangos de sobreestimación de los parámetros (Esquivel y Huerta, 2007).

Finalmente, en el método de Kernel todos los municipios tratados se comparan con un promedio ponderado de todos los municipios de control no tratados; para ello se utiliza una ponderación inversamente proporcional a la distancia entre las puntuaciones de 
propensión de los municipios tratados y los de control (Esquivel y Huerta, 2007). ${ }^{5}$

Este trabajo hace un emparejamiento con reemplazo para el método del vecino más cercano; es decir, un municipio no tratado puede ser emparejado con uno o más municipios tratados, lo que reduce los problemas de pruning o de descarte de municipios no violentos para el emparejamiento, pero que a su vez se traduce en un incremento de overlapping o traslape de casos. No obstante, en las pruebas estadísticas se muestra que el uso de reemplazo mejora significativamente el emparejamiento de los municipios, lo que resulta en estimadores más confiables del efecto promedio de la violencia sobre la emigración interna municipal.

Por otro lado, una de las limitaciones de este tipo de técnicas es el uso de una variable binaria (dummy) para medir el efecto de la violencia, lo que provoca la pérdida de detalle de los niveles de violencia experimentados por los municipios al sólo dividirlos por alta y baja violencia. Por lo anterior, se opta por analizar sólo al $20 \%$ de los municipios con mayores tasas de homicidios en cada periodo, ya que, como lo demuestran trabajos previos, no es hasta que se rebasa un umbral de violencia cuando ésta tiene un efecto sobre las tasas de emigración interna, por lo que partimos del supuesto de que al seleccionar al 20\% de los municipios más violentos de México, todos éstos han superado el umbral de violencia. No obstante, en el desarrollo del trabajo también se hicieron pruebas con el 10 y el $25 \%$ de los municipios más violentos del país.

Una vez obtenido el grupo de municipios de contraste o el llamado escenario contrafactual de bajas tasas de violencia, se procede a comparar las tasas de emigración interna municipal de los municipios tratados con las tasas de emigración de los municipios emparejados, en donde la diferencia de tasas entre ambos grupos serán los efectos promedio del tratamiento sobre las tasas de emigración interna municipales para los municipios más violentos de México. El supuesto fundamental de esta metodología radica en asumir que el nivel de violencia de los municipios no es aleatorio y depende en

${ }^{5}$ Para una explicación más detallada del Propensity Score Matching y de los métodos de emparejamiento, véase Rosaenbaum y Rubin (1983) y Baum (2013). 
última instancia de variables socioeconómicas y demográficas observables. Además de que la eficacia de esta técnica estará condicionada porque el grupo de tratamiento tenga observaciones de comparación cercanas o similares respecto a su puntaje de propensión.

Por otro lado, debido a los problemas que podría ocasionar el tamaño de los municipios y de sus respectivas tasas de homicidios en el análisis, este trabajo optó en principio por utilizar las tasas de homicidios de cada periodo, es decir el acumulado de cinco años con el propósito de reducir las variaciones ocasionadas por el tamaño de los municipios. Además, se hicieron pruebas de modelos descartando a los municipios con las menores poblaciones de la nación. No obstante, los resultados de estas pruebas no mostraron diferencias significativas con los modelos completos, por lo que se prefirió tomar al total de municipios del país.

\section{Resultados}

\section{Panorama geográfico de la violencia y la emigración}

En los mapas siguientes (Mapa 1) se muestran las tasas de homicidios por cada mil habitantes a nivel municipal por quinquenios, con el propósito de identificar las regiones y los municipios del país con mayores niveles de violencia y su evolución en las últimas dos décadas. Para el periodo 1995-1999 se observa que la violencia en México se concentraba en municipios de Oaxaca, Guerrero y Michoacán, además de diversos municipios vecinos entre Sinaloa, Chihuahua y Durango en el denominado triángulo dorado, donde históricamente se han cultivado grandes cantidades de mariguana y amapola. Posteriormente, para el periodo 2000-2004 se observa un descenso en las tasas de homicidios de algunos de los municipios de Oaxaca, Guerrero y Michoacán, aunque sigue persistiendo la violencia en municipios del triángulo dorado, sobre todo en algunas regiones de Sinaloa y Chihuahua.

Para el periodo 2005-2009, en el que se da el inicio de la denominada guerra contra el narcotráfico, hay un incremento de la violencia hacia diversos municipios del noroeste del país en los estados 
de Chihuahua, Sinaloa, Durango, Sonora y Baja California. Además, aumentó la violencia en municipios de Guerrero y Michoacán como resultado de los operativos de las fuerzas armadas para abatir a los líderes de organizaciones criminales en estas entidades, lo que provocó la división de los grupos criminales y su enfrentamiento por el control de los territorios (CMDPDH, 2014).

Finalmente, en el periodo 2010-2014 se da un incremento y expansión de las tasas de homicidios en diversas regiones del país, y se propaga la violencia hacia otros municipios de Chihuahua, Sinaloa, Durango y Sonora, con una concentración de altas tasas en municipios cercanos al triángulo dorado y en algunos de los municipios frontera con Estados Unidos, que es explicada en mayor parte por los enfrentamientos de los grupos criminales en busca del control de la producción y el trasiego de drogas hacia ese país (IDMC, 2018). En Guerrero y Michoacán se extiende la violencia hacia otros municipios y hacia otras entidades como Colima y Jalisco; es en este periodo cuando surgen diversos grupos de autodefensas comunitarias ante la creciente violencia en sus comunidades y la incapacidad de las autoridades para brindarles seguridad (Cherem, 2016).

Además, en este último periodo de análisis es donde se consolida y propaga una nueva zona con altos niveles de violencia al noreste del país, constituida por diversos municipios de Tamaulipas y Nuevo León, que si bien ya mostraba algunos brotes de violencia desde quinquenios anteriores en algunos de sus municipios fronterizos, no fue hasta el periodo 2010-2014 cuando la violencia alcanzó niveles iguales o superiores a los registrados en la zona noroeste y cuyas causas principales responden a problemas similares, como son los enfrentamientos armados entre grupos criminales por el control del territorio y de las rutas de trasiego de drogas hacia Estados Unidos (Zárate y López, 2016).

Para poder describir los cambios en la migración interna en México durante el periodo 1995-2015 usamos tasas de emigración interna municipales en años-persona. La disponibilidad de información permite generar mapas para tres quinquenios, en donde se puede observar un panorama general de las regiones del país con mayores niveles de emigración interna y sus cambios en las últimas dos décadas (Mapa 2). En el periodo 1995-2000 se observa que las mayores ta- 
sas de emigración interna municipal se localizan en el norte del país en municipios de Sinaloa, Sonora, Durango, Coahuila y Zacatecas; mientras que en la región del Pacífico se encuentran municipios de Colima, Jalisco, Michoacán y Guerrero. Para el centro del país se da una enorme concentración de altas tasas en las alcaldías de la Ciudad de México, y en el sur de la nación hay altos niveles de emigración en municipios de Veracruz, Tabasco y Chiapas. La mayor parte de estos movimientos responden al cambio del modelo económico del país y a los procesos de urbanización y metropolización que se han dado en los últimos años, al ser mayoritariamente una migración urbana-urbana que se da de ciudades de gran tamaño a ciudades de mediano tamaño (Sobrino, 2010).

\section{Mapa 1}

Tasas de homicidios municipales por cada mil habitantes, 1995-2014

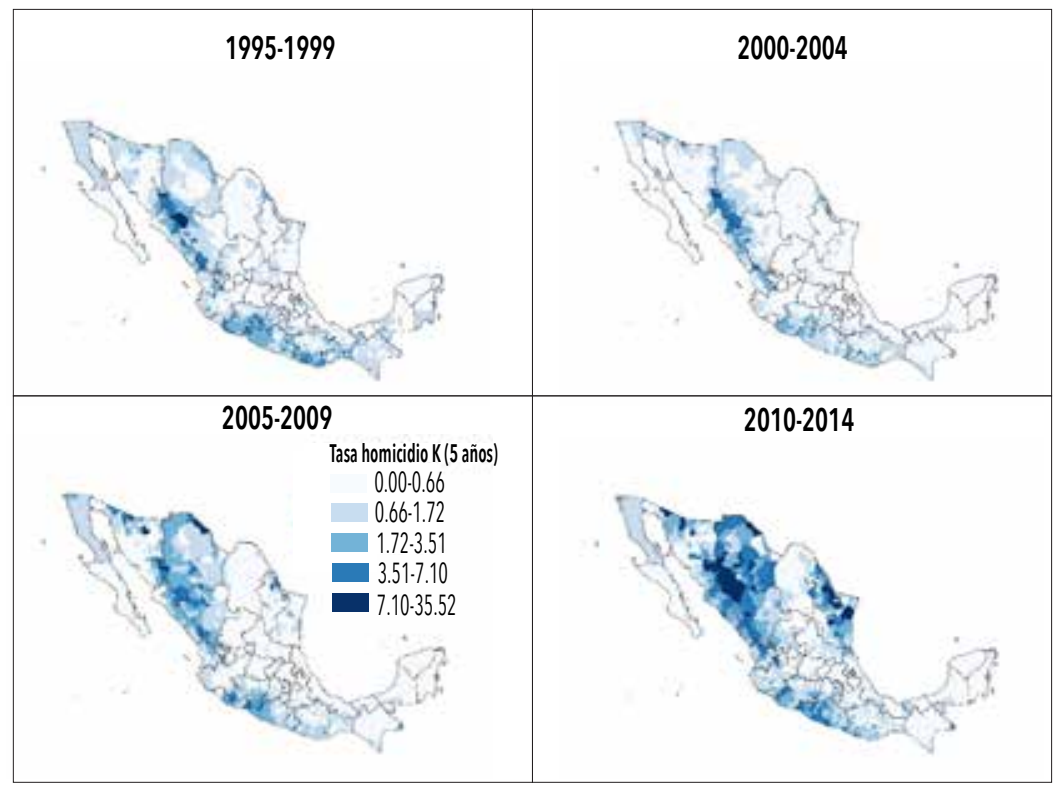

Fuente: Elaboración propia con datos de los registros administrativos del INEGI (2019) y el software QGIS V 2.18. 
Para el quinquenio 2005-2010 se observan reducciones en la región centro y sur del país, mientras que en la zona norte de México y en municipios de las costas de Colima, Jalisco y Michoacán se da una persistencia de altas tasas en algunos de sus municipios. Además, hay una propagación hacia municipios al norte de Baja California, Sonora, Chihuahua, Coahuila, Nuevo León y Tamaulipas. Finalmente, en este periodo también se ven altas tasas de emigración en algunos municipios de Campeche y en algunas de las alcaldías de la Ciudad de México. Así, la emigración sigue respondiendo a los factores anteriores, como son los procesos de metropolización y urbanización del país, pero también puede llegar a estar relacionada con la crisis financiera y económica de 2008-2009, cuyos problemas se agudizaron en las ciudades fronterizas del país ligadas a la industria maquiladora de exportación, y con la estrategia de seguridad implementada en 2007 que trajo consigo problemas de seguridad y de violencia que repercutieron en distintos municipios del norte de la nación y de Guerrero y Michoacán (IDMC, 2018).

Finalmente, en el periodo 2010-2015, pese al descenso general de la emigración interna municipal en la mayoría de los municipios del país, se dio un incremento y cambios en las tasas de emigración en diversos municipios de Sonora, Sinaloa, Chihuahua, Durango, Coahuila y Nuevo León, con un ascenso particular en municipios del triángulo dorado o cercanos a éste. También hubo una concentración e incremento de las tasas en algunos de los municipios de Jalisco y Guerrero, que si bien no pueden explicarse en su totalidad por las secuelas de la crisis financiera de 2008-2009 y del aumento de la violencia a partir de la guerra contra el narcotráfico, pueden explicar en parte el incremento de la emigración en algunos de estos municipios.

\section{Características socioeconómicas y demográficas de los municipios con mayores niveles de violencia en México, 1995-2015}

A partir de las tasas de homicidios municipales por quinquenios, se seleccionó al 20\% de los municipios con mayores tasas de homicidios (quintil V) para cada uno de los periodos analizados. Así, se 
seleccionaron 484 municipios en el periodo 1995-2000, $487 \mathrm{mu}-$ nicipios en el periodo 2005-2010, y 491 municipios en el periodo 2010-2015. En principio se procede a comparar las características socioeconómicas y demográficas de este grupo de municipios respecto al resto de los municipios del país (quintiles I al IV), así como los cambios en su composición y en las características socioeconómicas y demográficas.

\section{Mapa 2}

Tasas de emigración interna municipal por cada mil habitantes, 1995-2015

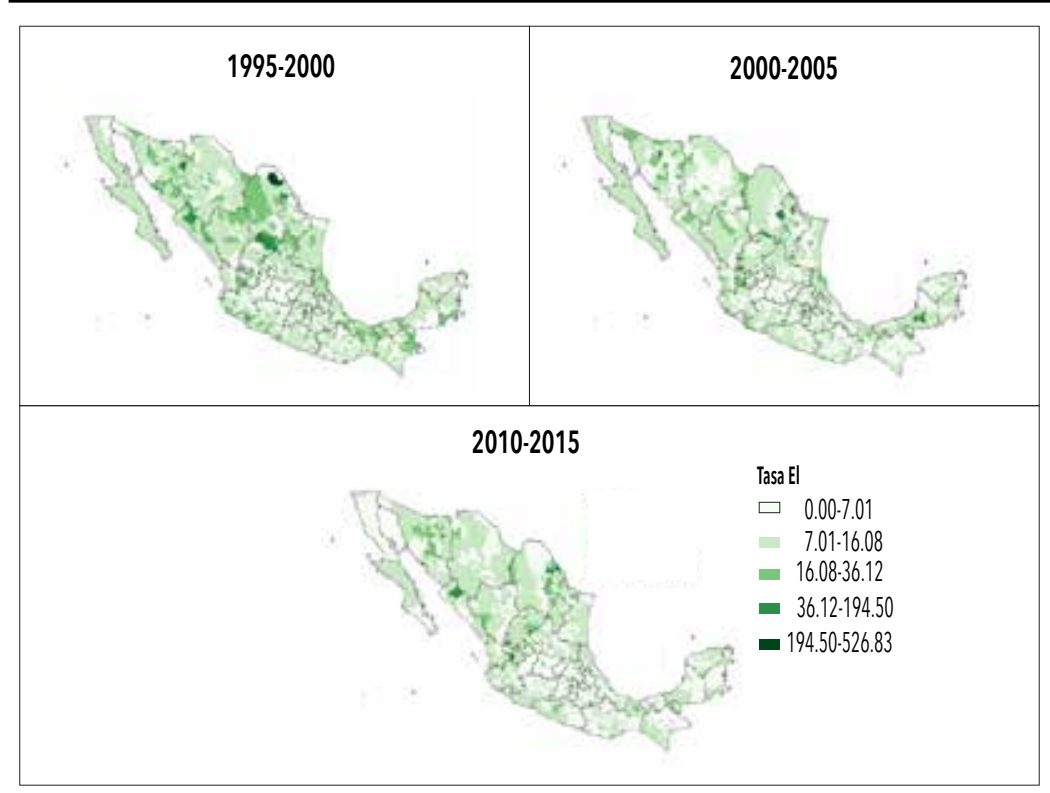

Fuente: Elaboración propia con datos de los CPV 2000 y 2010, la EI 2015 y el software QGIS V 2.18.

Como se puede ver en el Cuadro 2, el 20\% de los municipios con mayores niveles de violencia en el periodo 1995-2000 muestran un promedio de tasa de emigración de 51.78 emigrantes por cada mil habitantes, un nivel $7.70 \%$ mayor al registrado por el resto de los municipios del país. El 37.7\% de los municipios del quintil V tuvie- 
ron una población de 15 mil o más habitantes en 1995, mientras que para el resto de los municipios el porcentaje fue de $42.2 \%$. Respecto al grado de marginación, los municipios con mayores niveles de violencia tuvieron en promedio niveles altos, mientras que el resto mostraron niveles medios de marginación.

Para el periodo $2005-2010$, el $20 \%$ de los municipios con los mayores niveles de violencia en México reportaron en promedio una tasa de emigración interna de 49.96 emigrantes por cada mil habitantes, mientras que el $80 \%$ restante de los municipios mostraron una tasa promedio $13.1 \%$ menor. La presión demográfica fue 5.3\% mayor en los municipios más violentos, comparado con el resto del país. Respecto a la mediana del salario, en los municipios del quintil $\mathrm{V}$ ésta fue en promedio $11.1 \%$ mayor que en el resto de los quintiles. Además, los municipios con alta violencia mostraron niveles altos de marginación, menores porcentajes de población nacida fuera de estos municipios, y un mayor índice absoluto de intensidad migratoria (IAIM) hacia Estados Unidos.

Finalmente, para el periodo 2010-2015 se observa que las tasas de emigración interna del quintil $\mathrm{V}$ fueron en promedio $32.3 \%$ mayores a las del resto de los municipios; se siguió observando más presión demográfica en los municipios de menor violencia, y siguen persistiendo los mejores salarios en los municipios de mayor violencia. Además, el porcentaje de desocupación y el índice de Gini muestran mayores niveles para los municipios con mayor violencia. Por último, el promedio en el índice de intensidad migratoria a Estados Unidos y del porcentaje de población nacida en otro lugar dentro de México como proxys de las redes migratorias internas e internacionales, son mayores para los municipios con altas tasas de violencia.

El Cuadro 2 nos permite identificar algunas de las diferencias observables de los municipios con alta violencia respecto a sus contrapartes de menores tasas de homicidios para cada uno de los tres periodos analizados, concluyendo que en los periodos 2005-2010 y 2010-2015 los municipios de mayor violencia tienden a mostrar mayores tasas de emigración interna, mayor presión demográfica, menor porcentaje de municipios urbanos, mayor nivel de ingresos, mayor porcentaje de desocupación, mayor desigualdad, niveles medios y altos de marginación, y mayor índice de intensidad migrato- 
ria a Estados Unidos. No obstante, dado el sesgo de selección en los grupos analizados, no es posible concluir que los efectos promedio de la violencia sobre la tasa de emigración interna sean la diferencia entre estos dos grupos, dado que quedan fuera otros factores que pueden llegar a afectar el que un municipio tenga o no altas tasas de violencia.

\section{Cuadro 2}

Promedios de las características socioeconómicas y demográficas de los municipios más violentos (quintil V) y del resto de municipios de México, 1995-2015

\begin{tabular}{|c|c|c|c|c|c|c|}
\hline \multirow[b]{2}{*}{ Variables } & \multicolumn{2}{|c|}{$1995-2000$} & \multicolumn{2}{|c|}{$2005-2010$} & \multicolumn{2}{|c|}{$2010-2015$} \\
\hline & $\begin{array}{c}\text { Quintil } \\
\text { I-IV }\end{array}$ & $\underset{V}{\text { Quintil }}$ & $\begin{array}{c}\text { Quintil } \\
\text { I-IV }\end{array}$ & $\underset{V}{\text { Quintil }}$ & $\begin{array}{c}\text { Quintil } \\
I-I V\end{array}$ & $\underset{V}{\text { Quintil }}$ \\
\hline $\begin{array}{l}\text { Tasa emigración } \\
\text { interna }\end{array}$ & 48.07 & 51.78 & 40.79 & 46.96 & 36.71 & 48.59 \\
\hline Presión demográfica & 64.57 & 64.26 & 82.69 & 87.03 & 71.65 & 77.16 \\
\hline Municipio urbano & $42.2 \%$ & $37.7 \%$ & $44.4 \%$ & $36.3 \%$ & $46.6 \%$ & $40.7 \%$ \\
\hline $\begin{array}{l}\text { Mediana del } \\
\text { salario/1000 }\end{array}$ & & & 1.40 & 1.56 & 2.99 & 3.47 \\
\hline$\%$ desocupados & & & $1.0 \%$ & $1.1 \%$ & $4.2 \%$ & $5.1 \%$ \\
\hline Gini & 40.12 & 40.01 & 41.41 & 42.35 & 37.13 & 38.55 \\
\hline Grado marginación & Medio & Alto & Medio & Alto & Medio & Medio \\
\hline$\%$ nacidos otro lugar & & & $8.5 \%$ & $8.0 \%$ & $8.4 \%$ & $10.3 \%$ \\
\hline IAIM & & & 3.61 & 4.69 & 3.57 & 4.43 \\
\hline $\mathrm{N}$ & 1943 & 485 & 1954 & 487 & 1965 & 491 \\
\hline
\end{tabular}

Fuente: Elaboración propia con datos de los CPV 2000 y 2010, de la EI 2015, Conapo, Coneval e INEGI.

\section{Ubicación de los municipios con muy alta violencia en México para los tres periodos de análisis}

Como se mencionó en el apartado anterior, la selección de los municipios de tratamiento, es decir, de los municipios con mayores niveles de violencia en México, se hizo a partir del 20\% de los municipios del país con las mayores tasas de homicidios por quinquenio, 
lo que arroja un grupo de tratamiento en el periodo 1995-1999 de 484 casos, de 487 para 2005-2009, y de 491 municipios para 20102014. Más adelante se muestran los mapas en donde se ubican tanto los municipios tratados como los no tratados para cada periodo, con el objetivo de identificar su distribución y concentración a lo largo y ancho del territorio nacional.

Para el periodo 1995-2000 las entidades con mayores porcentajes de municipios seleccionados respecto al total de sus municipios fueron: Guerrero (72.4\%), Baja California (60.0\%), Sinaloa (55.6\%), Chihuahua (37.3\%), Morelos (36.4\%), Oaxaca (35.8\%), Durango (30.8\%), Michoacán (28.3\%) y Estado de México (26.2\%). Estas nueve entidades concentraron al $79.4 \%$ del total de municipios seleccionados, es decir, con las mayores tasas de violencia durante este quinquenio.

Posteriormente, en el periodo 2005-2010 hubo una concentración de la violencia y de los municipios seleccionados en las siguientes entidades: Sinaloa (83.3\% del total de sus municipios), Chihuahua (79.1\%), Durango (71.8\%), Guerrero (67.9\%), Baja California (60.0\%), Michoacán (41.6\%), Sonora (38.9\%) y Oaxaca (27.19\%). Ello provocó que estas ocho entidades contuvieran al 78.4\% de los municipios con tratamiento en este periodo.

Nuevamente, en el periodo 2010-2015 hubo un crecimiento de las tasas de homicidios y su concentración en algunas regiones y entidades del país, provocando que los mayores porcentajes de municipios seleccionados respecto al total de sus municipios se dieran en: Chihuahua (91.0\%), Sinaloa (88.9\%), Guerrero (67.9\%), Durango (64.1\%), Nuevo León (62.8\%), Tamaulipas (53.5\%), Sonora (47.2\%), Nayarit (45.0\%), Baja California (40.0\%), Colima (40.0\%), Morelos (33.3\%) y Michoacán (27.4\%), que en conjunto sumaron el $61.7 \%$ de los municipios con mayor violencia.

Al comparar los municipios con tratamiento en los diferentes quinquenios, sobresalen los casos de Nuevo León, Chihuahua, Tamaulipas, Colima, Durango, Sinaloa y Sonora, que mostraron importantes crecimientos en su porcentaje de municipios seleccionados a lo largo de los tres periodos, y por ende del incremento de la violencia dentro de sus territorios, llegando a seleccionar a por lo menos el $40 \%$ de sus municipios durante el último periodo de análisis. 


\section{Mapa 3}

Municipios seleccionados para tratamiento

a partir de sus tasas de homicidios por cada mil habitantes, 1995-2000, 2005-2010 y 2010-2015

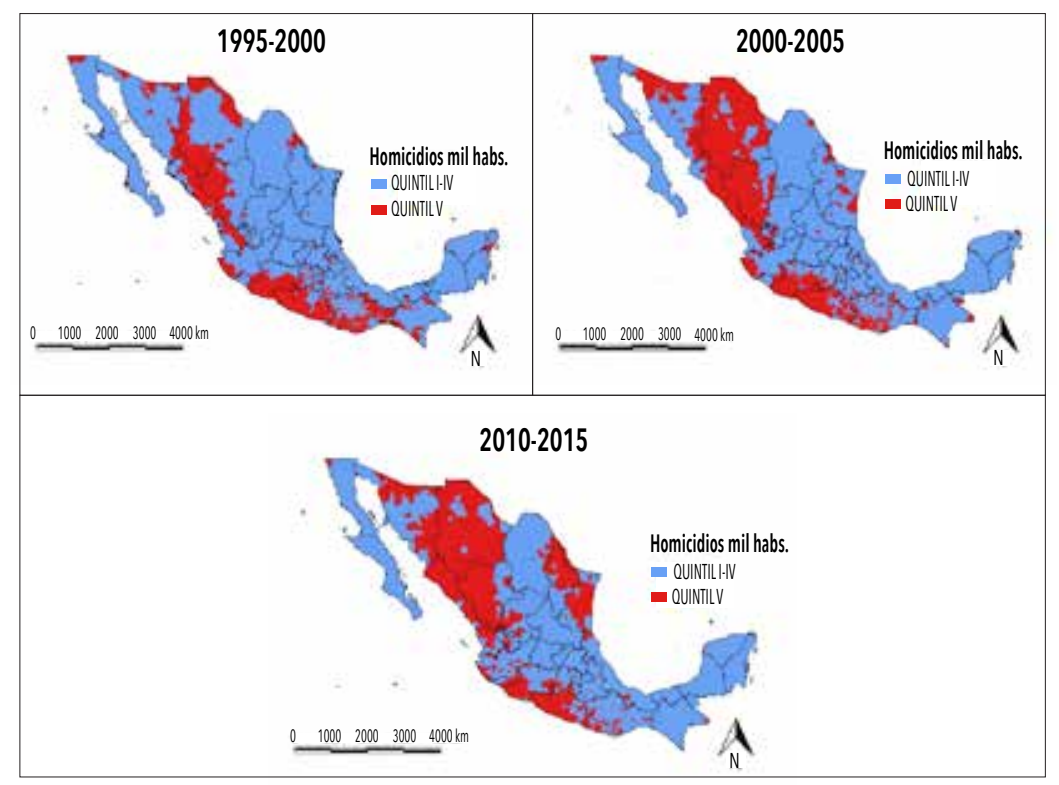

Fuente: Elaboración propia con datos de los registros del INEGI, los CPV 2000 y 2010, la EI 2015 y el software QGIS V 2.18.

\section{Creación de los escenarios contrafactuales}

Una vez determinados los municipios de tratamiento o con altas tasas de violencia, se procede a determinar el índice de propensión para cada uno de los municipios de México a partir de las variables socioeconómicas y demográficas propuestas mediante el desarrollo de modelos de regresión logística binaria (logit) relacionados con la probabilidad de que un municipio muestre altas tasas de homicidios para cada periodo de análisis. En el Cuadro 3 se tienen los resultados de los modelos logit y de las variables relacionadas con la probabi- 
lidad de que un municipio en México pertenezca al grupo de municipios con tratamiento, es decir, que muestre altas tasas de violencia para cada uno de los tres periodos analizados.

Adicionalmente, se incluye un segundo modelo para el periodo 2010-2015, en donde se agrega la variable de presencia de narcomensajes en los municipios durante el periodo 2006 a 2010; el resultado de esto es un incremento del pseudo R2 en el modelo, además de un efecto significativo y positivo sobre la probabilidad de que un municipio tenga altas tasas de violencia y, por tanto, sea parte del tratamiento.

\section{Cuadro 3}

Resultados de los modelos logit sobre la probabilidad de que un municipio tenga altas tasas de violencia en México, para periodos $1995-2000,2005-2010$ y 2010-2015

\begin{tabular}{|c|c|c|c|c|}
\hline Logit & $1995-2000$ & $2005-2010$ & $2010-2015$ & $\begin{array}{r}2010-2015 \\
\text { (modelo 2) } \\
\end{array}$ \\
\hline Tratamiento & Coef. & Coef. & Coef. & Coef. \\
\hline Presión & -0.002 & $0.010 * * *$ & $0.015 * * *$ & $0.016 * * *$ \\
\hline Urbano & -0.151 & -0.181 & $-0.348 * *$ & $-0.988 * * *$ \\
\hline Salario/1000 & & $1.660 * * *$ & $0.677 * * *$ & $0.536 * * *$ \\
\hline \% desocupación & & 0.009 & $0.050 * * *$ & $0.040^{* *}$ \\
\hline Gini & $0.111 * *$ & $0.037 * *$ & $0.047 * *$ & 0.010 \\
\hline Marginación (muy baja) & 1 & & & \\
\hline Baja & 0.446 & $0.923 * * *$ & $0.714 * *$ & $0.728 * *$ \\
\hline Media & $0.94 * * *$ & $1.286 * * *$ & $0.782 * * *$ & $0.728 * *$ \\
\hline Alta & $1.748 * * *$ & $2.041 * * *$ & $0.970 * * *$ & $0.996 * * *$ \\
\hline Muy alta & $2.43 * * *$ & $3.497 * * *$ & $2.151 * * *$ & $2.138 * * *$ \\
\hline Redes México & & 0.005 & $0.013^{*}$ & 0.009 \\
\hline Redes Estados Unidos & & $0.040 * *$ & $0.071 * * *$ & $0.062 * * *$ \\
\hline Narcomensajes (no) & & & & $1.747 * * *$ \\
\hline Constante & $-6.93 * * *$ & $-8.137 * * *$ & $-7.913 * * *$ & $-6.653 * * *$ \\
\hline Pseudo R2 & 0.0677 & 0.1084 & 0.0979 & 0.1613 \\
\hline
\end{tabular}

$* \mathrm{p}<0.05, * * \mathrm{p}<0.01, * * * \mathrm{p}<0.001$.

Fuente: Elaboración propia con el software STATA v 14. 
Una vez desarrollados los modelos, se calcula el índice de propensión para cada municipio tanto del grupo con tratamiento como para aquel sin tratamiento, y se procede a su emparejamiento mediante las técnicas del vecino más cercano, radio y Kernel (véase el Anexo).

Los distintos tipos de emparejamientos de los municipios tratados muestran que, en los tres periodos analizados, estas técnicas permitieron el empate de todos los municipios con tratamiento, con excepción del método del radio, que, para el periodo 1995-2010, empató a 471 de 484 municipios analizados; para el periodo 2005-2010 fueron 483 de 487, y para el periodo 2010-2015 fueron 484 de 491. Por tanto, fue posible la creación de los escenarios contrafactuales de menores niveles de violencia al comparar a municipios con similares características socioeconómicas y demográficas, pero con distintos niveles de violencia. El resultado del emparejamiento a partir de los índices de propensión es una reducción en la variación de las características socioeconómicas y demográficas entre los municipios con tratamiento y los municipios empatados, lo cual puede ser demostrado a partir de pruebas de diferencias de medias estandarizadas y gráficos de densidades del puntaje de propensión estimado antes y después del emparejamiento (véase el Anexo).

\section{Efectos de la violencia sobre las tasas de emigración interna municipal para los municipios más violentos de México}

Una vez controladas las características socioeconómicas y demográficas, y después del emparejamiento de los municipios con altas tasas de violencia con otros con características similares pero que no muestran altas tasas de violencia, se procede a comparar las tasas de emigración interna municipales de los municipios con tratamiento (violentos) con las tasas de emigración interna de los municipios emparejados (con menor violencia). El Cuadro 4 muestra las diferencias de tasas sin el emparejamiento por puntuación y la diferencia de tasas una vez emparejados los municipios mediante los tres métodos de emparejamiento utilizados. 


\section{Cuadro 4}

Diferencias promedio en las tasas de emigración interna municipal de los municipios con tratamiento y de los municipios empatados

\begin{tabular}{llcccccc}
\hline Periodo & Método & $\begin{array}{c}\text { Núm. } \\
\text { empatados }\end{array}$ & Tratado & Control & Diferencia & S.E. & T-stat \\
\hline & No & & 10.16 & 9.75 & 0.41 & 0.81 & 0.51 \\
& empatado & & & & & & \\
1995-2000 & Vecino & 484 & 10.16 & 8.75 & 1.41 & 1.03 & 1.37 \\
& Radio & 471 & 10.19 & 9.13 & 1.06 & 0.64 & 1.66 \\
& Kernel & 484 & 10.16 & 9.06 & 1.10 & 0.63 & 1.75 \\
\hline & No & & 9.07 & 7.99 & 1.08 & 0.65 & 1.67 \\
& empatado & & & & & & \\
2005-2010 & Vecino & 487 & 9.07 & 7.49 & 1.57 & 0.54 & 2.90 \\
& Radio & 483 & 9.06 & 7.53 & 1.53 & 0.65 & 2.36 \\
& Kernel & 487 & 9.07 & 7.50 & 1.56 & 0.62 & 2.52 \\
\hline & No & & 9.71 & 7.34 & 2.37 & 0.56 & 4.25 \\
& empatado & & & & & & \\
2010-2015 & Vecino & 491 & 9.71 & 7.69 & 2.02 & 0.53 & 3.81 \\
& Radio & 484 & 9.59 & 7.79 & 1.80 & 0.57 & 3.18 \\
& Kernel & 491 & 9.71 & 7.81 & 1.91 & 0.56 & 3.42 \\
\hline & No & & 9.71 & 7.34 & 2.37 & 0.56 & 4.25 \\
& empatado & & & & & & \\
2010-2015 & Vecino & 491 & 9.71 & 7.75 & 1.96 & 0.55 & 3.59 \\
(modelo 2) & Radio & 473 & 9.57 & 7.49 & 2.09 & 0.63 & 3.30 \\
& Kernel & 491 & 9.71 & 7.68 & 2.04 & 0.62 & 3.30 \\
\hline
\end{tabular}

Fuente: Elaboración propia con el software STATA v 14.

El resultado es que para el periodo 1995-2000 los efectos promedio de la violencia sobre las tasas de emigración interna del 20\% de los municipios con mayores tasas de homicidios fueron de entre 1.06 y 1.41 unidades, por encima de los 0.41 que se obtenían de sólo comparar las tasas promedio de ambos grupos sin tomar en cuenta las demás variables relacionadas con los niveles de violencia municipal. Estas diferencias obtenidas implican que, en promedio, entre el 10.4 y el $13.9 \%$ de la emigración interna municipal en estos municipios fue explicada por sus altos niveles de violencia. 
Por otro lado, para el periodo 2005-2010 inicialmente la comparación de las tasas entre los municipios con alta violencia y el resto de los municipios arrojaron una diferencia de tasas de 1.08 unidades. Sin embargo, una vez controladas las variables socioeconómicas y demográficas de los municipios asociadas a sus altos niveles de violencia, se puede observar que la diferencia de tasas fue de entre 1.53 y 1.57 unidades, lo que quiere decir que en promedio entre el $16.9 \mathrm{y}$ el $17.3 \%$ de la emigración interna en estos municipios fue explicada como consecuencia de sus altos niveles de violencia.

Para el periodo 2010-2015, cuando se registraron las mayores tasas de violencia municipal, se tiene que los efectos promedios de la violencia sobre las tasas de emigración interna de los municipios con tratamiento fueron de entre 1.80 y 2.02 unidades, cifra menor a las 2.37 unidades obtenidas de comparar las tasas de emigración de los municipios más violentos con el resto de los municipios del país; estimando que, una vez controlando los factores socioeconómicos y demográficos asociados, el resultado es que la violencia explicó entre el 18.8 y el $20.8 \%$ del total de la emigración interna en los municipios más violentos de México de 2010 a 2015.

En tanto que para el modelo 2 del periodo 2010-2015 se tiene que los efectos promedios de la violencia sobre las tasas de emigración interna en los municipios tratados, una vez incluida la variable referente a los enfrentamientos criminales dentro de las características observadas de los municipios, fueron de entre 1.96 y 2.09 unidades, lo que explica entre el 20.2 y el $21.8 \%$ del total de la emigración interna de los municipios más violentos de México para el periodo 2010 a 2015.

Estos resultados del análisis contrafactual muestran que la violencia, y en específico los homicidios, han tenido un impacto importante sobre la emigración interna de los municipios con mayor violencia en el país en las últimas dos décadas. Tal efecto es mayor a lo estimado por algunas organizaciones y encuestas que sólo hacen referencia a las víctimas directas de la violencia que fueron desplazadas de manera forzada como resultado de algún acto violento o de una amenaza directa en contra de ellos o de alguno de los miembros de su familia, dejando fuera a todas las personas que, ante contextos prolongados de violencia generalizada, vieron reducir su bienestar social y económi- 
co, lo que a largo plazo los motivó a dejar sus lugares de origen, sin que fueran necesariamente amenazados o violentados.

\section{Conclusiones y futuras investigaciones}

Esta investigación evaluó los efectos reales de la violencia en el 20\% de los municipios con mayores tasas de homicidios en México para los periodos 1995-2000, 2005-2010 y 2010-2015. Se mostró en principio que las tasas de homicidios en general han tendido a aumentar después de la puesta en marcha de la estrategia de seguridad del presidente Felipe Calderón en diciembre de 2006, particularmente en los municipios del norte del país y de la costa del Pacífico. El aumento de la violencia como consecuencia de la división de los grupos criminales y de su posterior enfrentamiento por el control de la producción, distribución y trasiego de drogas hacia Estados Unidos provocó una concentración de la violencia en la mayor parte de los municipios de Chihuahua, Sinaloa, Guerrero, Durango, Nuevo León y Tamaulipas, los cuales mostraron las mayores tasas de homicidios entre 2005 y 2015.

Para poder evaluar los efectos reales de la violencia sobre las tasas de emigración interna municipal del 20\% de los municipios con mayores tasas de homicidios entre 1995 y 2015, fue necesario la creación de escenarios contrafactuales de bajas tasas de violencia, y la posterior contrastación de sus tasas de emigración interna municipal. A partir de diversas técnicas de emparejamiento se desarrollaron los escenarios contrafactuales, demostrando que la violencia en los municipios de México que más la han padecido durante las últimas dos décadas ha explicado entre el 10.4 y el $21.8 \%$ de su emigración interna municipal, al haber incrementado sus tasas de emigración en promedio entre 1.06 y 2.09 unidades extra por cuestiones relacionadas a la violencia, lo que representa efectos mayores a los que se esperarían si sólo se compararan las tasas de emigración interna de estos municipios con alta violencia respecto al resto de los municipios de la nación.

Los resultados muestran que en México la violencia ha provocado desplazamientos internos mayores a los que se estiman al sólo 
contar a los desplazamientos directos y reactivos, particularmente en las entidades del norte y en algunas entidades del Pacífico. Por tanto, la estrategia de seguridad implementada desde diciembre de 2006 no sólo provocó la división y reacomodo de las organizaciones criminales por el abatimiento de algunos de sus principales líderes, sino que también aumentaron la violencia y diversos problemas sociales, tales como los desplazamientos internos forzados.

Ante estos hechos, y dada la magnitud de los efectos de la violencia sobre los movimientos poblacionales recientes, es necesario el diseño de leyes y políticas públicas que cuantifiquen de manera adecuada al total de víctimas del desplazamiento interno por cuestiones de violencia, para que posteriormente protejan y brinden asistencia a las víctimas en las distintas etapas del fenómeno, lo que lleve a su reparación integral mediante el regreso asistido y seguro a sus comunidades de origen o mediante su inserción y desarrollo pleno en los lugares de destino.

No obstante, esta investigación no está libre de limitaciones. Primero, ofrece únicamente información del $20 \%$ de los municipios con mayores niveles de homicidios en México, aunque durante el desarrollo del trabajo también se hicieron pruebas con el 10 y el $25 \%$ de los municipios más violentos de la nación, llegando a resultados similares, lo que deja fuera al resto de municipios y a otros indicadores y delitos relacionados con el aumento de la violencia en el país. Esto implica que los resultados están sesgados principalmente a municipios del norte de México, en donde las condiciones de violencia se vieron reflejadas en el incremento de los homicidios relacionados con el crimen organizado, pero no necesariamente con otros tipos de delitos, como son los diversos tipos de robos, secuestros y amenazas.

Además, no toma en cuenta el efecto de la distancia entre el lugar de origen y el lugar de destino de los desplazamientos forzados, mismo que escapa a los objetivos de este artículo pero que es objeto de estudio del autor en otros análisis. Esto es importante considerarlo pues puede determinar que un desplazamiento sea interno o internacional, dada su cercanía con las fronteras internacionales. Por otro lado, no analiza los efectos fijos de los municipios, lo que puede provocar que los resultados pueden llegar a estar sesgados, al no 
considerar el efecto en conjunto que alcanzan los municipios en una misma región o entidad del país.

Por su parte, una de las desventajas de este tipo de técnicas de análisis radica en que depende del supuesto de que los altos niveles de violencia en los municipios de México se explican, en última instancia, por características observables, por lo que la existencia de otras variables no observadas $u$ omitidas puede tener un impacto significativo sobre el que un municipio llegue a tener altas tasas de violencia y de emigración, lo que podría llegar a provocar sesgos en los resultados obtenidos.

Por ello, es necesario que futuras investigaciones, a partir de diversas técnicas, analicen aspectos tales como el efecto de la distancia sobre los desplazamientos forzados, sobre todo por los niveles de violencia observados en la frontera norte pues, como la literatura lo señala, las víctimas tienden a desplazarse a zonas cercanas de sus lugares de origen por los altos costos del desplazamiento o por el deseo de regresar a sus lugares de origen y, para muchos, el cruce de la frontera internacional puede ser más factible y seguro que migrar internamente.

Así, futuras investigaciones deben buscar evaluar también los efectos de la violencia sobre la migración interna, internacional y de retorno, como resultado de las actuales condiciones de inseguridad y violencia por las que atraviesa el país, lo que puede llegar a repercutir tanto en la salida de las personas como en la selección de los lugares de destino de los migrantes nacionales e internacionales. 


\section{Anexo}

\section{Gráfica A1}

Emparejamiento de los municipios con altos niveles de violencia respecto a otros municipios de México con menores niveles de violencia, por método de emparejamiento

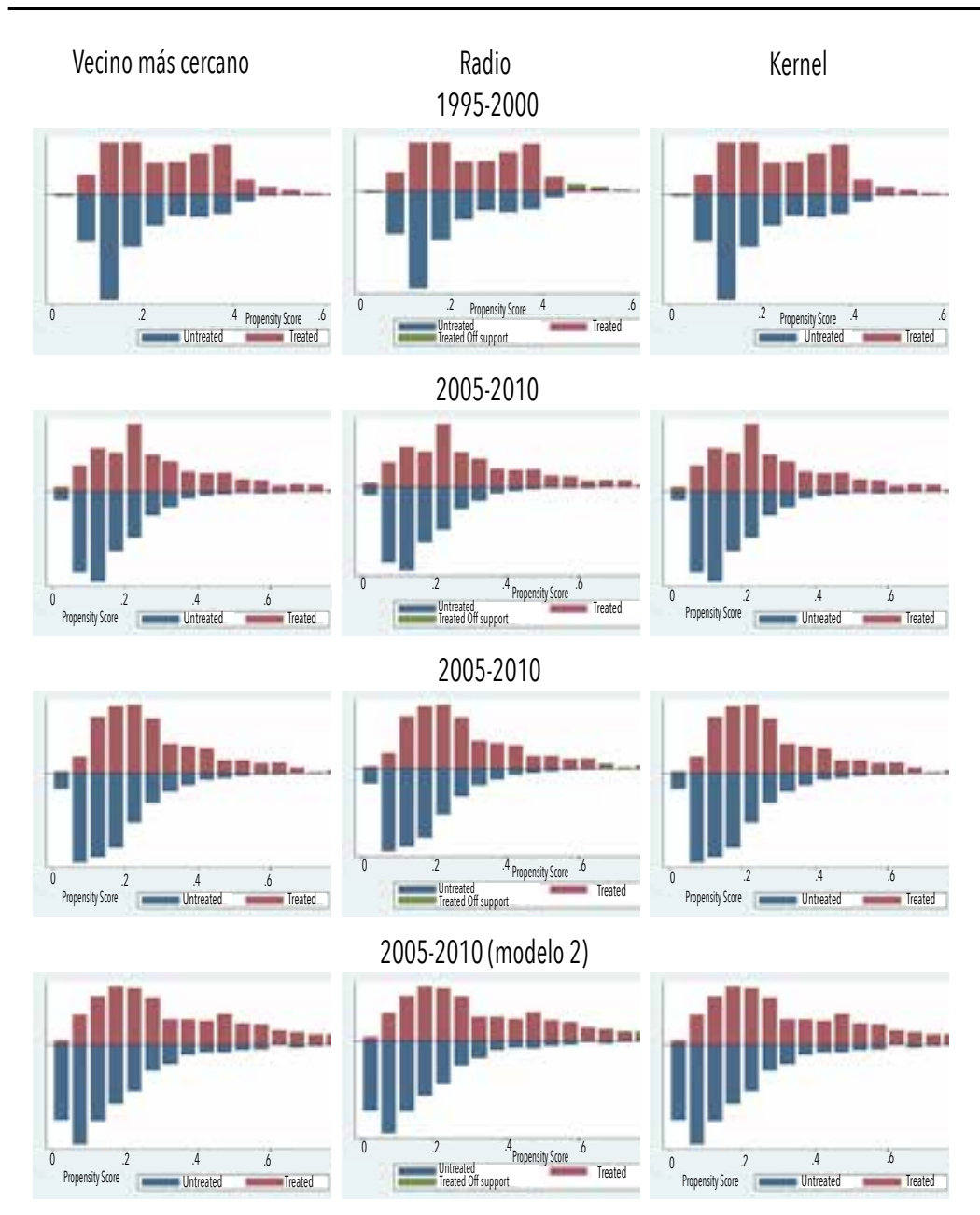

Fuente: Elaboración propia a partir del método Propensity Score Matching y del software Stata v. 14. 


\section{Gráfica A2}

Diferencias de medias estandarizadas entre municipios tratados y no tratados, según método de emparejamiento

Vecino más cercano
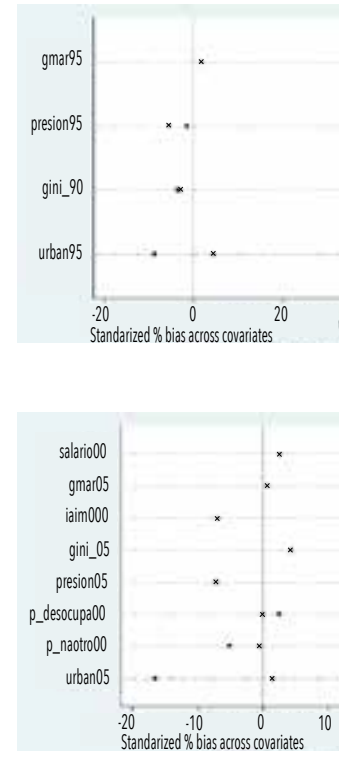

Radio

1995-2000

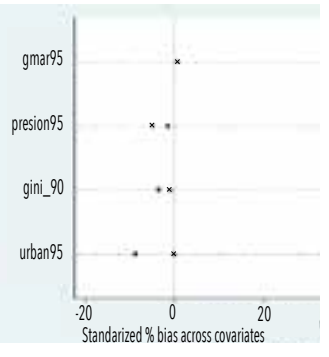

2005-2010

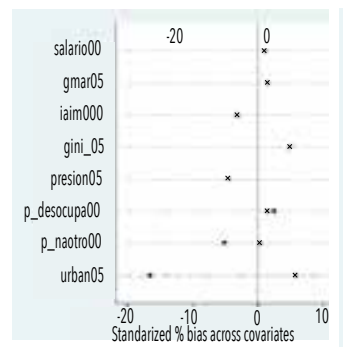

Kernel
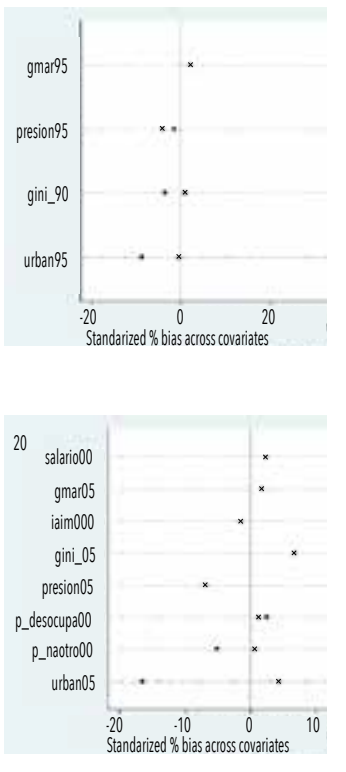

(continúa) 


\section{Gráfica A2}

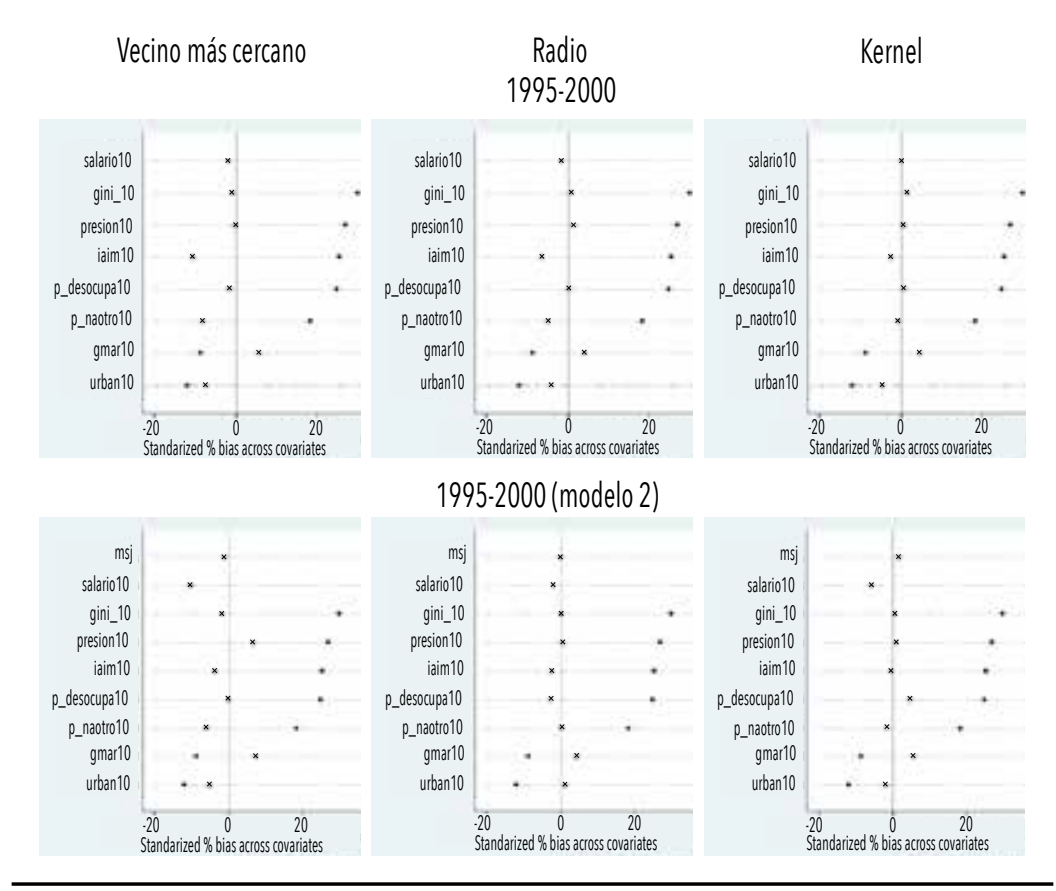

Fuente: Elaboración propia a partir del Propensity Score Matching y de las técnicas de emparejamiento: vecino más cercano, radio y Kernel. 


\section{Cuadro A1}

Pruebas de diferencias de medias estandarizadas por método de emparejamiento

\begin{tabular}{|c|c|c|c|c|c|c|c|}
\hline Periodo & Muestra & Método & $\begin{array}{c}\text { Pseudo } \\
\text { R2 }\end{array}$ & $\begin{array}{c}\text { LR } \\
\text { chi2 }\end{array}$ & $p>$ chi2 & $\begin{array}{c}\text { Mean } \\
\text { Bias }\end{array}$ & $\begin{array}{l}\text { Med } \\
\text { Bias }\end{array}$ \\
\hline \multirow{4}{*}{$1995-2000$} & No emparejado & & 0.067 & 163.03 & 0.000 & 17.9 & 14.3 \\
\hline & \multirow{3}{*}{ Emparejado } & Vecino & 0.001 & 1.88 & 0.966 & 3.0 & 2.7 \\
\hline & & Radio & 0.001 & 0.92 & 0.996 & 1.5 & 1.1 \\
\hline & & Kernel & 0.001 & 1.02 & 0.994 & 1.8 & 1.4 \\
\hline \multirow{4}{*}{$2005-2010$} & No emparejado & & 0.107 & 261.88 & 0.000 & 15.4 & 16.4 \\
\hline & \multirow{3}{*}{ Emparejado } & Vecino & 0.004 & 4.76 & 0.942 & 3.1 & 2.6 \\
\hline & & Radio & 0.002 & 2.45 & 0.996 & 2.6 & 2.0 \\
\hline & & Kernel & 0.002 & 2.54 & 0.995 & 2.5 & 1.5 \\
\hline \multirow{4}{*}{$2010-2015$} & No emparejado & & 0.099 & 243.70 & 0.000 & 22.3 & 20.8 \\
\hline & \multirow{3}{*}{ Emparejado } & Vecino & 0.005 & 7.20 & 0.783 & 4.0 & 3.0 \\
\hline & & Radio & 0.002 & 3.14 & 0.989 & 2.2 & 1.7 \\
\hline & & Kernel & 0.002 & 2.06 & 0.998 & 1.4 & 0.8 \\
\hline \multirow{4}{*}{$\begin{array}{l}2010-2015 \\
\text { (modelo 2) }\end{array}$} & No emparejado & & 0.164 & 402.28 & 0.000 & 26.1 & 22.8 \\
\hline & \multirow{3}{*}{ Emparejado } & Vecino & 0.007 & 9.28 & 0.679 & 4.7 & 4.5 \\
\hline & & Radio & 0.001 & 1.40 & 1.000 & 1.6 & 1.5 \\
\hline & & Kernel & 0.002 & 2.78 & 0.997 & 2.0 & 1.4 \\
\hline
\end{tabular}

Fuente: Elaboración propia a partir del Propensity Score Matching. 


\section{Gráfica A3}

Densidades del puntaje de propensión estimados sobre los grupos de tratamiento y de control, antes y después del emparejamiento

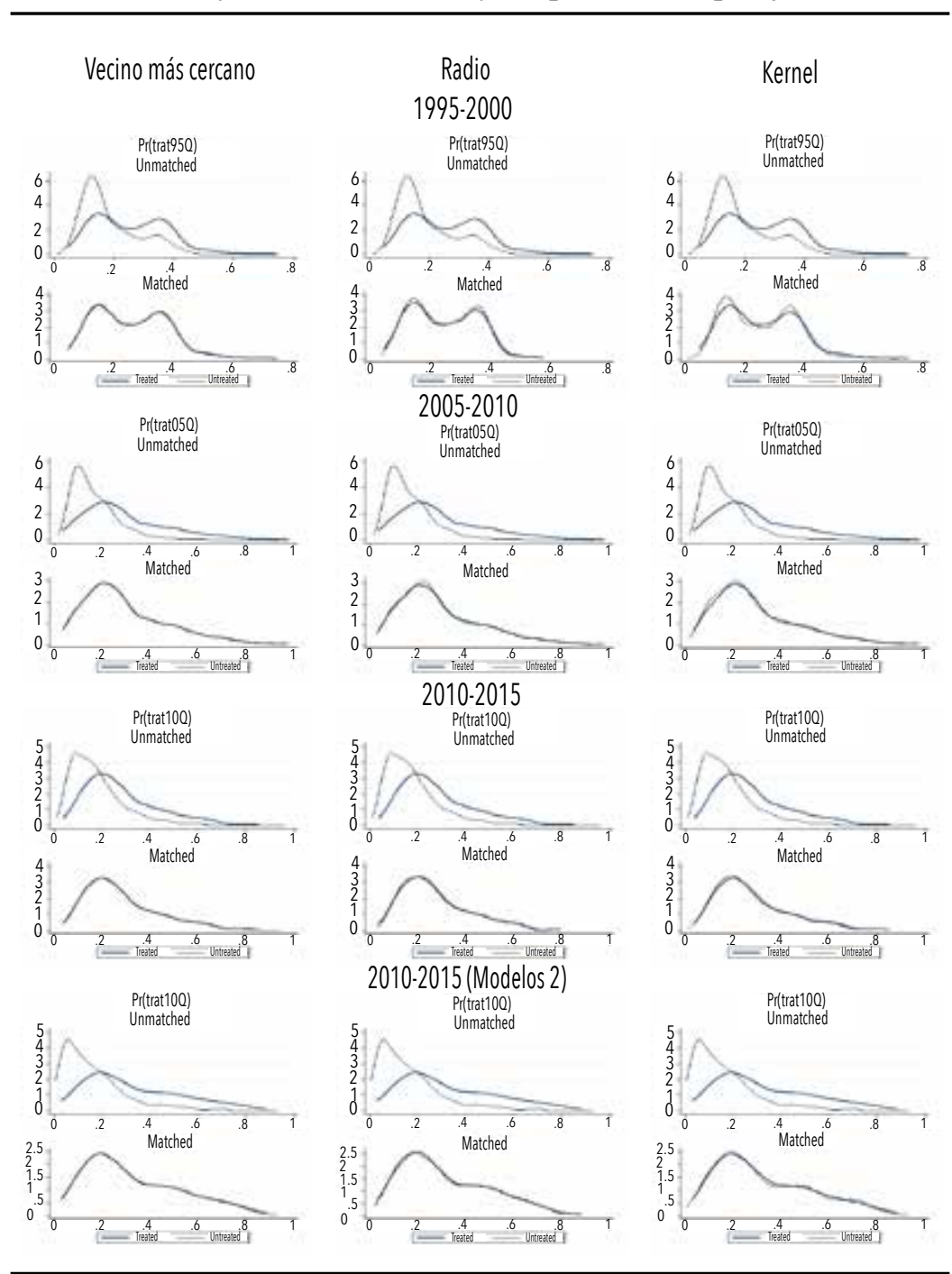

Fuente: Elaboración propia a partir de la técnica Propensity Score Matching. 


\section{Bibliografía}

Aburto, J. M., Beltrán-Sánchez, H., García-Guerrero, V. M. y Canudas-Romo, V. (2016). Homicides in Mexico reversed life expectancy gains for men and slowed them for women, 2000-10. Health Affairs, 35(1), 88-95. https://www.ncbi.nlm.nih.gov/ pmc/articles/PMC5453309/

ACNUR. (2018). Tendencias globales desplazamiento forzado en 2017. Alto Comisionado de las Naciones Unidas para los Refugiados. https://www.acnur.org/5b2956a04.pdf

Acosta, F. y Cruz, R. (2015). Factores económicos y sociales asociados a la migración interna en México. En R. Cruz Piñeiro y F. Acosta (coords.), Migración interna en México. Tendencias recientes en la movilidad interestatal (pp. 115-148). Tijuana: El Colegio de la Frontera Norte.

Alvarado, S. y Massey, D. (2010). In search of peace: Structural adjustment, violence and international migration. The Annals of the American Academy of Political and Social Science, 630(1), 137161. https://www.ncbi.nlm.nih.gov/pmc/articles/PMC3011825/

Arenas, E., Parker, S., Rubalcava, L. y Teruel, G. (2015). Evaluación del programa del Seguro Popular del 2002 al 2005. Impacto en la utilización de servicios médicos, en el gasto en salud y en el mercado laboral. El Trimestre Económico, 82(328), 807-845. http://www.eltrimestreeconomico.com.mx/index.php/te/article/ view/185/183

Banco Mundial. (2018). Población mundial 1960-2017. http://datos. bancomundial.org/indicador/SP.POP.TOTL

Bariagaber, A. (1997). Political violence and the uprooted in the horn of Africa. A study of refugee flows from Ethiopia. Journal of Black Studies, 28(1), 26-42. https://www.jstor.org/ stable/2784892?seq=1\#metadata_info_tab_contents

Baum, C. F. (2013). Propensity score matching regression discontinuity limited dependent variables. Applied econometrics. (Documento de trabajo, EC823). Boston: Spring. http://fmwww. bc.edu/EC-C/S2013/823/EC823.S2013.nn12.slides.pdf

Cerón, J. A. y Hernández, M. (2017). Análisis del impacto del programa Oportunidades en el ingreso autónomo de sus benefi- 
ciarios. Economía Informa, 406, 62-79. http://www.economia. unam.mx/assets/pdfs/econinfo/406/06CeronHernandez.pdf

Cherem, A. (2016). Grupos de autodefensa: sin salida ante la violencia. (Tesis de licenciatura en Ciencia Política. Instituto Tecnológico Autónomo de México). http://departamentodeciencia politica.itam.mx/sites/default/files/u327/tesiscpol_alexische rem.pdf

CIDE. (2016). Registro de eventos (Guerra contra las drogas 20062011). Política de drogas. Ciudad de México: Centro de Investigación y Docencia Económicas. http://www.politicadedrogas. org/PPD/index.php/observatorio/categorias/id/8.html

CMDPDH. (2014). Desplazamiento interno forzado en México. Ciudad de México: Comisión Mexicana de Defensa y Promoción de los Derechos Humanos. http://www.cmdpdh.org/publicacionespdf/cmdpdh-desplazamiento-web.pdf

CMDPDH. (2019). Entre la invisibilidad y el abandono: un acercamiento cualitativo al desplazamiento interno forzado en México. Ciudad de México: Comisión Mexicana de Defensa y Promoción de los Derechos Humanos. http://www.cmdpdh.org/ publicaciones-pdf/cmdpdh-entre-la-invisibilidad-y-el-abandonoun-acercamiento-cualitativo-al-desplazamiento-interno-forzado -en-mexico.pdf

CNDH. (2016). Informe especial sobre desplazamiento forzado interno (DFI) en México. Ciudad de México: Comisión Nacional de los Derechos Humanos. http://www.cndh.org.mx/sites/all/ doc/Informes/Especiales/2016_IE_Desplazados.pdf

Conapo. (2017). Índice absoluto de intensidad migratoria México-Estados Unidos, 2000-2010. Ciudad de México: Consejo Nacional de Población. https://datos.gob.mx/busca/dataset/ indice-absoluto-de-intensidad-migratoria-mexico--estadosunidos-2000--2010

Coneval. (2017). Indicadores de pobreza, pobreza por ingresos, rezago social y Gini a nivel municipal, 1990, 2000, 2005 y 2010. Ciudad de México: Consejo Nacional de Evaluación de la Política de Desarrollo Social. https://datos.gob.mx/busca/ dataset/indicadores-de-pobreza-pobreza-por-ingresos-rezago social-y-gini-a-nivel-municipal1990-200-2010 
Durin, S. (2012). Los que la guerra desplazó: familias del noreste de México en el exilio. Desacatos, 38, 29-42. http://desacatos. ciesas.edu.mx/index.php/Desacatos/article/download/269/149

Enamorado, T., López-Calva, L., Rodríguez-Castelán, C. y Winkler, H. (2014). Income inequality and violent crime. Evidence from México's drug war. (Documento de Investigación, 6935). The World Bank. http://documents.worldbank.org/curated/en/ 236161468299090847/pdf/WPS6935.pdf

Esquivel, G. y Huerta-Pineda, A. (2007). Las remesas y la pobreza en México: un enfoque de pareo de puntuación de la propensión. Integración y Comercio, 11(27), 47-74. https://publications. iadb.org/publications/spanish/document/Revista-Integraci\%C 3\%B3n--Comercio-A\%C3\%B1o-11--No-27--Julio-diciembre -2007.pdf

Gutiérrez, E. y Rivero, E. (2012). Elaboración de diagnóstico: desplazamiento interno en México. Internal Displacement Monitoring Centre.

Ibañez, A. y Vélez, C. (2008). Civil conflict and forced migration: The micro determinants and welfare losses of displacement in Colombia. World Development, 36(4), 659-676. https://ideas. repec.org/a/eee/wdevel/v36y2008i4p659-676.html

IDMC. (2018). Internal displacement in México. Country Information 2017. Internal Displacement Monitoring Centre.

INEGI. (2017). Censos de Población y Vivienda 1940-2010. Aguascalientes, México: Instituto Nacional de Estadística y Geografía. https://www.inegi.org.mx/programas/ccpv/2020/

INEGI. (2018). Encuesta Intercensal 2015. Aguascalientes, México: Instituto Nacional de Estadística y Geografía. https:/www.inegi. org.mx/programas/intercensal/2015/

INEGI. (2019). Registros administrativos. Estadísticas vitales. Mortalidad. Aguascalientes, México: Instituto Nacional de Estadística y Geografía. https://www.inegi.org.mx/programas/mortalidad/

Martínez, P. (2016). Desplazamiento forzado: el saldo oculto de la guerra. Animal Político. http://www.animalpolitico.com/diez-deguerra/desplazados.html

Massey, D., Arango, J., Hugo, G., Kouaouci, A., Pellegrino, A. y Taylor, J. (1993). Theories of international migration. A review 
and appraisal. Population and Development Review, 19(3), 431466.https://www.jstor.org/stable/2938462?seq=1\#metadata_info tab_contents

Morales, M., Morales, O., Menchaca, A. y Sebastian, A. (2013). The Mexican drug war and the consequent population exodus: Transnational movement at the U.S.-Mexican border. Societies, 3(1), 1-24. https://ideas.repec.org/a/gam/jsoctx/v3y2013ilp80103d23 145.html

Morrison, A. (1993). Violence or economics: What drives internal migration in Guatemala? Economic Development and Cultural Change, 41(4), 817-831. https://www.journals.uchicago.edu/ doi/abs/10.1086/452049?mobileUi $=0$

ONU. (1998). Los principios rectores de los desplazamientos internos de la Organización de las Naciones Unidas. Derechos Humanos, éxodos en masa y personas desplazadas. Comisión de Derechos Humanos.

Ramírez, T. y Meza, L. (2012). Inseguridad pública y migración internacional en México. En T. Ramírez García y M. Á. Castillo (coords.), El estado de la migración. México ante los recientes desafios de la migración internacional (pp. 269-298). Ciudad de México: Consejo Nacional de Población.

Ríos, V. (2014). The role of drug-related violence and extortion in promoting Mexican migration: Unexpected consequences of a drug war. Latin American Research Review, 49(3), 199-217. https://scholar.harvard.edu/files/vrios/files/riosv2014_larr2014_ securityimmigration1.pdf

Rosenbaum, P. y Rubin, D. (1983). The central role of the propensity score in observational studies for causal effects. Biometrika, 70(1), 41-55. https://academic.oup.com/biomet/article/ $70 / 1 / 41 / 240879$

Sobrino, J. (2010). Migración interna en México durante el siglo XX. Ciudad de México: Consejo Nacional de Población.

UNODC. (2013). Global study on homicide 2013. Viena: United Nations Office on Drugs and Crime. https://www.unodc.org/ documents/gsh/pdfs/2014_GLOBAL_HOMICIDE_BOOK_ web.pdf 
Vélez, D., Vélez, M., Martell, E., Rodríguez, O., Fernández, J., Pérez, V., Díaz, C., Rivas, F., Fernández, L. y Cendejas, M. (2015). Homicidio: una mirada a la violencia en México. Ciudad de México: Observatorio Nacional Ciudadano de Seguridad, Justicia y Legalidad.

Zárate, A. y López, A. (2016). Estudio sobre la violencia en Tamaulipas: diagnóstico y acciones de respuesta. Seminario sobre Violencia y Paz. Conferencia Mexicana sobre Violencia y Paz desde lo Local, 20-22 de junio. El Colegio de México, A.C.

\section{Acerca del autor}

Oscar Rodríguez Chávez es doctor en Estudios de Población en El Colegio de México, A.C., maestro en Desarrollo Regional por El Colegio de la Frontera Norte, y licenciado en Economía Agrícola por la Universidad Autónoma Chapingo. Actualmente es profesor-investigador de El Colegio de la Frontera Norte. Ha trabajado como investigador del Observatorio Nacional Ciudadano de Seguridad, Justicia y Legalidad en el análisis estadístico de los datos de incidencia delictiva a nivel nacional, estatal y municipal. Además, ha colaborado con el Instituto Nacional de Estadística y Geografía y con la Comisión Nacional para el Desarrollo de los Pueblos Indígenas en el manejo de bases de datos y el análisis estadístico sobre temas relacionados con migración, desigualdad y pobreza. Es miembro del consejo editorial de la revista digital Estudios Interculturales, participa como articulista en el blog Observatorio Nacional Ciudadano del Universal Opinión, y ha publicado artículos en diversas revistas sobre temas de educación, pobreza, adultos mayores y migración. Sus líneas de investigación versan sobre migración, desigualdad y violencia. ORCID: https:// orcid.org/0000-0002-7255-0605

Recepción: 2 de agosto de 2019. Aceptación: 11 de diciembre de 2019. 